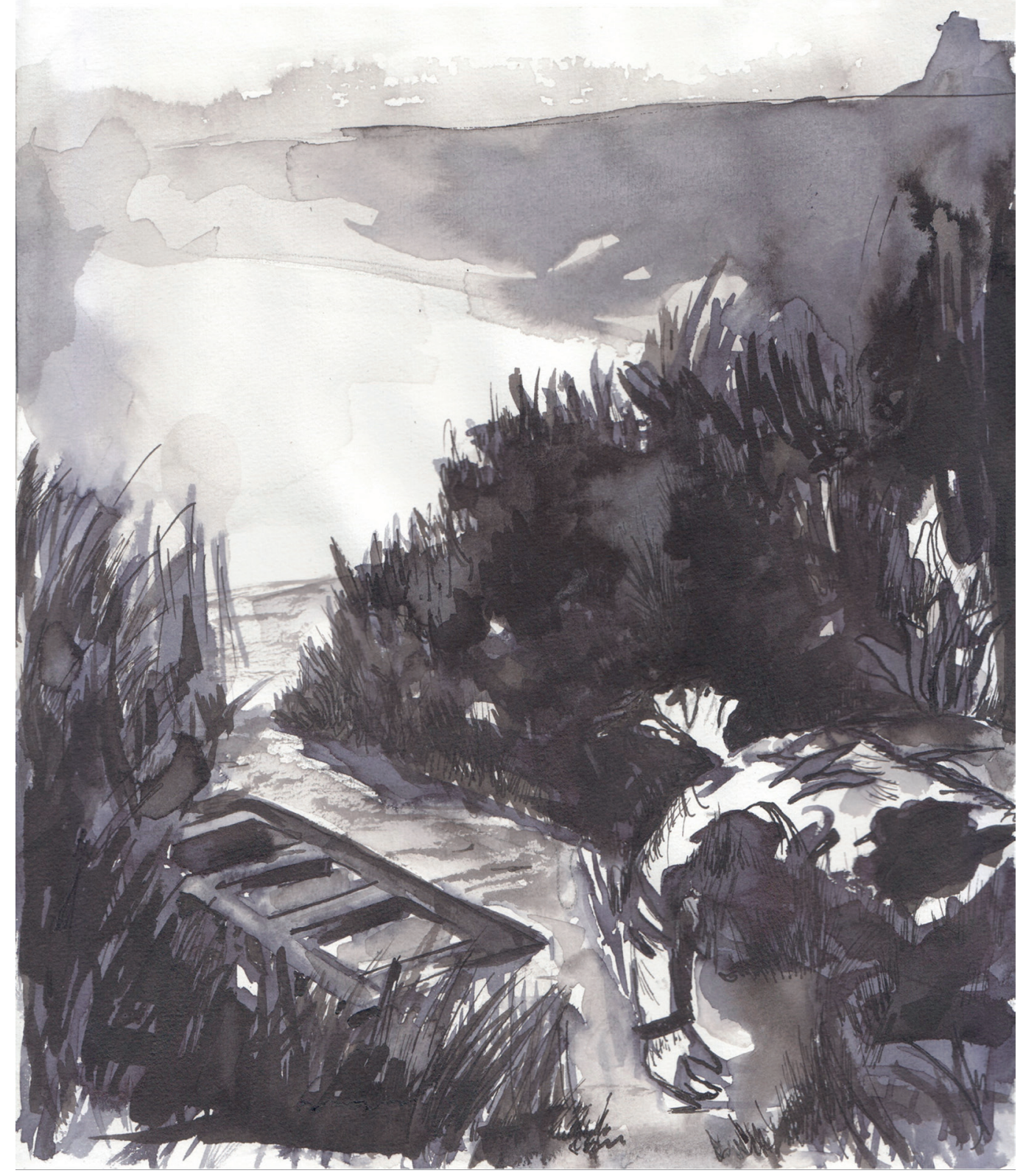

Ronda de vigilancia

Diego Zamora Cascante

Técnica: tintas sobre papel, 2018.

Ilustra el cuento

Ronda de vigilancia 



\section{Ronda de vigilancia}

Esteban González Sánchez.

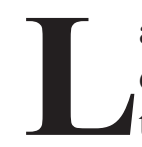
a ronda de búsqueda había empezado hacía casi media hora; no le gustaba llegar tarde porque el pusilánime del jefe ya le había llamado la atención por ser "el campeón de las tardías"; escupió largo y el gargajo resonó a flema. El foco McLite tenía baterías nuevas y le extrañó que Jaime o Marcos no hubieran pasado por este trillo de la orilla del río María Aguilar, no había ninguna cinta amarilla. A estas alturas del retraso, era mejor rastrear solo y luego unirse al coro de voces de reagrupación o si alguno encontraba "algo" lo verían llegar y aunque era obvio que había llegado tarde, ese sería un acontecimiento menor, debido al hallazgo, luego encontraría razones suficientes para justificarse como quien no quiere la cosa, después al jefe se le olvidaría momentáneamente el enojo, porque si encontramos "algo", él queda como los grandes.

Por respeto nunca le ha gustado llamar "algo" a lo que en realidad siempre están buscando, es decir, un cadáver, porque las esperanzas de encontrar a "alguien" con vida solo es una imagen que viaja en la mente de los familiares y seres queridos; por supuesto, al recibir la llamada del jefe, esa imagen se disuelve rápidamente en ininterrumpidos llantos o frases oscuras como un pozo de aprobación y un agradecimiento que abre la puerta a la ceremonia del funeral. Es mejor que el jefe no llame a los familiares de las víctimas, nunca puede dejar de lado su ego, sus ganas de sobresalir con ese tonito tan fuera de lugar, poco conciliador y en el peor de los casos, para morirse de la pena ajena, de ligue, más si reconoce a una familiar atractiva, o se excita por el tono de la voz..., para esa delicada función, lo mejor es que lo haga la vocera del OIJ, que tiene un tono suave y elegante, y aunque su labor es prioritariamente hablar frente a la prensa, lo cual hace con la mayor propiedad, a pesar de las preguntas incómodas y mal intencionadas de los periodistas, sabe esperar entre las pausas de dolor de los seres queridos; sobra agregar que se ve tan guapa en televisión, con esos ojotes pintados como egipcia, como en la vida real, siempre saluda, aún a uno que es de lo más bajo, o de su novio secreto, el administrador de recursos humanos, quien también tiene un tono reconfortante y es muy respetuoso, por dicha a mí nunca me ha tocado hacer algo así, ni podría hacerlo tampoco, ni me imagino yo frente al teléfono, con la jeta abierta y del otro lado hay una persona destrozada que está esperando, muy en el fondo, que le dé una buena noticia..., no ni pensarlo.

Ya han pasado varios minutos y está un poco desorientado, llueve cada vez más fuerte, constante, sabe que a lo lejos, más 
allá de los montículos de barro y el zacate chapeado, está la patrulla a la orilla de la carretera, las luces intermitentes se resbalan por las piedras mojadas y bajan por sus pestañas, de por sí, ¿desde cuándo tanto miedo?, más el ridículo de meterse en el charral por donde cree que empezaba el rastreo de hoy, ¿y si a última hora habían dado una orden nueva? Mejor dejarse de tantas playadas e ir a la patrulla, era más el ridículo que estaba haciendo, cuanto más se trata de disimular la torta, más se enseña.

El suampo de olores pútridos hace poca mella en los cayos nasales de Jaime, acostumbrado a este tipo de búsquedas, ya cuenta con un catálogo de hedores fácilmente clasificables: animales muertos distinguidos por leves tonalidades imaginarias, perros, un tono entre azul y gris que punza el cerebro, si es de un gato toca un poco más adentro en la garganta y el tono es más leve y huidizo; ratas, fácil de reconocer, se pega como una mucosidad a los ganglios linfáticos, no hay color porque siempre le han desagradado; aves, un tono cálido, y si es de humano, el olor es inconfundible, sobresale entre los demás animales que solo desechan los humanos en los ríos y entonces su cuerpo corre a buscar ese "algo", movido como cuando vio, boca abajo, a su hermano mayor dando vueltas en la poza, con la camisa celeste a cuadros y el cabello largo extendido.

El zacate son varejones largos y llenos de pelillos urticantes, se meten y ortigan, de la precisa se le rompió el zipper de la chaqueta y le comienza a picar el pecho y el cuello que rompe en canales con frenéticos arañazos, así el ardor supera la picazón; para colmo de males es alérgico al zacate, y ni pensar en las Talerdinas que dejó sobre la mesita de noche, ahí están, iluminadas por la lamparita dorada de tacto que tampoco apagó, en la carrera por haberse dormido. A los que les coge tarde les espera un pequeñito mar de congojas infernales; se echa alcohol en gel como untándose loción de afeitar.

Marcos debe ir a la cabeza de la búsqueda, como siempre, es el más aventajado, con un olfato más desarrollado y atento a los detalles que explica, como un rompecabezas, una vez que ha finalizado la búsqueda; su experiencia se ha nutrido de terremotos y de huracanes a lo largo de Centroamérica como el huracán César o el Mitch, y en varias ocasiones acompañó a los médicos sin fronteras. Todos esperan sus anécdotas mientras devoran el cafecito humeante y el pan blanco o tortillas calientes con natilla, ni el doctor que hablaba varios idiomas sabía lo que se hablaba en ese lugar de nombre rarísimo que no se me pega, más al noreste de Irak..., termina en tán, pero bueno, el caso es que el doctor Guillén toca a la criatura que habian sacado de entre los escombros de una escuela, y con una sonrisa que no sé de dónde la sacaba el doc, cada vez que tenía un paciente tan asustado como ese chiquillo, que podía tener qué, unos trece años talvez, bueno el caso es que por el momento la zona era segura y para no mover a la criatura le hacemos sombra al doc con unas mantas, en ese calor, y empieza a tocarlo por las costillas y el pecho, las piernitas, y la criatura comienza a hacer unos gestos, que el doctor veía con una atención, que entonces de la intriga yo veía la cara del doc, que sin moverse ni pestañar miraba la cara del pobrecito, las 
zonas que tocaba, la boca que se cerraba o los párpados apretados y las manos del chiquillo, que uno diría que solo son muecas de dolor, y a cada movimiento el doc las iba como apuntando en su mente; me acuerdo bien de los ojos del doc y sus anteojos, y al rato volvía a sonreír y daba las órdenes a los camilleros y a los enfermeros de qué hacer, qué tenía roto la criatura por dentro... yo creo que diagnosticaba a la perfección, siempre me limpiaba el doc.

La próxima no vuelvo a llegar tarde, juepucha, un descuido y se me pasan las birras, pero es que es mucha la tensión de este brete y yo siempre he sido muy sensible, muy hombre eso sí, pero muy sensible, por todo lloro, y uno explota por más jupa que le dé al asunto, puta, ¡cuánta maldad! y con las birras y las cubitas siempre me entra un sueño que estoy seguro de que apagué el despertador y me volví a dormir, y ¡ay Dios!, ¿qué majé? Ay no, por Dios, un bracito, jueputa foco, el pito, jacá está....!, ¡ACÁ ESTÁ!...

De cuclillas, como de aquí a allá, qué pueden ser, como cinco metros talvez, como un depredador en medio banquete, parece que le brillaron los ojos, cubierto de noche, se me paraliza el corazón y siento un escozor frío por todo el cuerpo, ¡se me viene!, como si no pisara el suampo, no lo puedo creer, con razón ayer no habíamos encontrado el cuerpecito; siento que se acerca, me ataca, casi no me puedo mover, pero lo siento acosarme y mi cuerpo es el que reacciona primero y siento que se me zafa de las manos, lo trato de agarrar porque sé que está armado, no sé con qué, ya me hirió pero ni importancia le doy por la adrenalina, y siento la sangre calientica debajo de la camiseta y de la chaqueta, se me escapan por momentos los brazos de él que son como agarrarse de palos podridos de lo mojado y embarrialado que está, y en medio de los gruñidos y el forcejeo entré completamente en mí y le zampo ese pichazo con el antebrazo por toda la jeta y una patada con los punta de acero por las costillas, y me caigo de espaldas pero del susto me levanto y a como puedo le empiezo a repartir un concierto de manazos y también me pega y me separa la cara con las manos abiertas, pero del susto y la adrenalina le sigo dando porque un descuido y me mata, por suerte escucho bulla y voces conocidas, la de Jaime y otros, y atrás mío la de Marcos que me ilumina para que le siga dando al hijueputa que estaba noqueado estirando los brazos como perro envenenado y yo que le sigo dando y Marquitos que me separa a la fuerza al ratito, jadeando, cuando ya llegaban los otros.

Y claro, quedo como un héroe, y la herida es cosa seria, casi que me cabían estos dos dedos así para adentro, y esa sed que me tenía, pero yo sigo como loco con las pupilas dilatadas y sudando frío al ratito y de fijo superhediondo, porque es el río más sucio de Chepe, hasta me enredé con un pedazo de alambre seguro todo herrumbrado y lo primero que hicieron fue limpiarme las heridas y venga la antitetánica, la anti hepatitis- $B$, suero y duérmase al rato que va de emergencia, dicen por la radio, para la sala de operación, en el San Juan o el México, se deciden por el México, y yo como gato asustado con tanta luz roja, azul y anaranjada y el escándalo de la ambulancia, todo rapidísimo; si con decirle que al rato ya hasta había llegado la prensa y cuando voy en la camilla para 
la sala de operación, me entero por una enfermera de que son los de canal 4, y entonces la enfermera Chacón dice, ahi está esa zorra, y se me iluminan los ojos, porque es la preciosura de las noticias de las once "pe-Eme", y si me viene a entrevistar así encamillado, como héroe de guerra, oiga, me hubiera sentido igual que cuando güila me pusieron a atajar, porque soy muy malo y al malo le toca atajar, bueno y todos me hacen barrera y el tito de Alberoni le mete ese patadón y yo atento y me doy cuenta de que el mae tiró, pero no veo la bola, porque los de enfrente me tapan, se cubren y se corren, se abren los muy pendejos y pasa la bola Molten como un rayo, de esas que eran duritas, que uno las picaba y sonaban por toda la calle y me da en la mera ñata y caigo de espaldas llorando, y entonces lo mejor, de lo mejor, uy, es que todavía es un bombón, uy, aparece Sabrina y se agacha para verme, y yo corto en seco el llanto, me quedó un bigotillo de sangre, y la sonadera de mocos y claro que se da cuenta de la emoción mía, que me hago el valiente, si a través de las lágrimas estaba ella, clarísima, con sus cejas anchas y el lunarcito en la boca, todos los hijupuetas haciendo ronda, y se medio ríe y el hermano Alberoni le pide que me dé un beso, ella se ríe como en broma y como por miedo que tenía de que yo no lo acusara, porque era cosa seria la mamá de ellos, o no sé por qué, pero se agacha, se recoge el pelo, pone las manos sobre sus muslos y me da el beso en la frente, y párese y siga la mejenga, luego la veo de reojo limpiándose la boca y una risilla. Bueno, pues la tita del canal estaba que quería entrar, pero por supuesto no la dejaron, yo iba pal quirófano y ya está.

El asesino había vuelto a la escena del crimen y arrastraba el cuerpo del pequeño David Alonso que se encontraba oculto en una alcantarilla de desagüe cubierta por matorrales, a trescientos metros de donde los cuerpos de búsqueda y emergencia de la Cruz Roja, en su mayoría voluntarios, habían empezado el rastreo cerca del río María Aguilar; por suerte, el cruzrojista Manuel Obregón Jiménez, a quien vemos en pantalla, quien había llegado tarde a la misión de rescate, decidió iniciar labores por su cuenta y se encontró con la víctima y el asesino, con quien tuvo un enfrentamiento y fue herido de consideración con un arma blanca en su costado... 